\title{
ON THE ROLE OF SWITCHING COSTS AND DECISION REVERSIBILITY IN INFORMATION TECHNOLOGY ADOPTION AND INVESTMENT
}

Dmitriy V. Chulkov iD http://orcid.org/0000-0003-0083-7815

Indiana University, School of Business, Kokomo, Indiana, United States

\begin{abstract}
Managerial decisions on the adoption of innovative technologies by a firm are made under conditions of uncertainty and must account for network externalities that imply the benefit of a technology is received not only from its intrinsic payoff, but also from the size of the network of other adopters. The theoretical model presented in this study demonstrates that for firms evaluating information technology investment with network effects key determinants of the technology selection pattern are adoption reversibility and switching costs. If switching costs are sufficiently high to make technology adoption irreversible then safer established technologies have an advantage as choosing a riskier untested technology opens the firm to the risk of being stranded without a network of followers. With lower switching costs, the technology adoption decision is reversible which provides an advantage to riskier untested technologies. A discussion of empirical evidence on adoption patterns in information technology provides application for the theoretical model.
\end{abstract}

Keywords: Information technology; technology adoption; switching costs; reversible decisions.

Manuscript first received: 2017/Apr/09. Manuscript accepted: 2017/Oct/08

Address for correspondence:

Dmitriy V. Chulkov, Professor of Economics and Management Information Systems in the School of Business at Indiana University Kokomo, Indiana, USA. E-mail: dchulkov@iuk.edu 


\section{INTRODUCTION}

In the information technology (IT) area, managerial decisions on adoption of new innovative technologies face a number of challenges. The process of technological innovation is characterized by inherent uncertainty. Investments in new technologies have varied levels of risk as newer innovative technologies that offer improved performance may also offer a lower likelihood of successful development (Krishnan and Bhattacharya, 2002). Furthermore, IT adoption decisions may be influenced by choices of other economic agents. With a network externality, the benefit to a firm of choosing a technology consists of its intrinsic payoff plus the "network" value from others adopting the same technology (Farrell and Saloner, 1986; Katz and Shapiro, 1986).

Research on technology adoption in management information systems (MIS) identified several conceptual models and general frameworks for such decisions including the technology acceptance model (TAM) and the unified theory of acceptance and use of technology (Venkatesh et al., 2003, 2012; Gangwar et al., 2014; Roy, 2017) as well as specific variables and success factors that influence adoption behavior (e.g. Kamal, 2006; Ghezzi et al., 2013). Meanwhile, a different approach prevailed in the area of economic analysis that focused on mathematical modeling of specific cause-and-effect relationships in the technology adoption process. The purpose of this study is to extend the economic theories on technology adoption when network externalities are present, specifically for the case of information technology. The focus is on identifying the role of switching costs and reversibility of the technology choices made by the firm.

A prominent example of adapting the economic analysis of network externalities to IT investment decisions is presented by Au and Kauffman (2001) who model technology adoption for the electronic bill presentment and payment (EBPP) industry. Their model considers a firm's irreversible choice between two competing technologies - a safer established technology, and a riskier unproven technology that may ultimately turn out to be superior. The study of Au and Kauffman shows that firms are more likely to adopt the safer existing technology, even though the untested technology may be superior. These results follow from the assumption that information technology adoption by the firm is not reversible, and once chosen a technology will be continually used. This assumption was originally proposed in the models of technology adoption by Choi (1997) as well as Choi and Thum (1998).

Case study evidence, however, suggests that technology choice in IT does not have to be irreversible, and firms may change their technology decisions and switch to alternative technologies by incurring switching costs. One case study of choosing between a safer and a riskier technology is provided by Krishnan and Bhattacharya (2002). The case involves Dell computer manufacturer selecting the technology for portable computer batteries. The safer option was to use the tested nickelmetal-hybrid (NiMH) batteries, while the riskier option was the lithium-ion technology (LIon). The technology choice was not irreversible, as Dell could change the design of its laptops by incurring a switching cost. The riskier but ultimately more promising LIon technology was selected in this case. The size of switching costs is identified as a key factor influencing the technology adoption pattern in recent empirical studies (e.g. Zhou et al., 2015).

The main contribution of this study is an original theoretical model that significantly extends the existing studies of Choi (1997) as well as Au and Kauffman (2001). While these studies suggest that there is an advantage to selecting the safer technology, the model constructed below identifies how with sufficiently low switching costs there are benefits to selecting the riskier technology which was the ultimate outcome in the Dell case as discussed by Krishnan and Bhattacharya (2002). 
Unlike the broader conceptual models of technology acceptance and use (TAM and UTAUT), the economic model constructed below focuses on the specific relationship between the IT technology selection pattern at the organizational level and the ease of switching between technologies after the adoption decision has been made. The analytical results also provide managerial implications for IT decision makers. They suggest that a firm selecting between technological solutions that do not involve irreversible commitments will see a benefit of trying a riskier untested technology. In contrast, if switching costs are sufficiently high and effectively make the adoption decision irreversible, then a safer technology provides an advantage to the firm. This reinforces the central role of the switching cost structure in IT adoption decisions.

The article is organized as follows. The next section presents a review of the relevant literature and defines key concepts for the development of the theoretical model. Section 3 presents the analytical model of technology choice with network externalities and different levels of switching costs. A discussion of empirical evidence on network externalities and switching costs in IT industries follows in Section 4. The final section reviews managerial implications and provides a conclusion.

\section{LITERATURE REVIEW}

This study complements two separate strands of research on technology adoption. In the economic literature, adoption of new technologies is explored through theoretical models that focus on mathematical modeling of the impact of various factors on the timing of technology choices made by the firm (Katz and Shapiro, 1986; Choi and Thum, 1998; Farzin et al., 1998; Hagspiel et al., 2015). In contrast, the MIS literature focuses on conceptual models including the technology acceptance model (TAM) and the unified theory of acceptance and use of technology - UTAUT (Venkatesh et al., 2003). TAM focuses on factors such as perceived usefulness and ease of use in determining an individual's attitude toward and use of IT. UTAUT integrates key factors including expected performance of the new technology, effort, and social influences, with moderating variables such as age, gender, experience, and voluntariness. These conceptual MIS models are then explored empirically as the impact of specific variables that influence technology adoption behavior is identified (Venkatesh et al., 2012; Kamal, 2006; Ghezzi et al., 2013; Roy, 2017).

The two modeling approaches - economic models and conceptual models of TAM and UTAUT - are complementary as they address different aspects of the technology adoption decision. Economic models are fundamentally based on the analysis of costs and benefits and focus on the best interest of the firm. TAM and UTAUT models explore the acceptance and ultimate use of new technologies.

\section{Network Externalities and Technology Adoption}

Information technology adoption is typically affected by network externalities because the benefits to a firm from choosing a technology come not only from its intrinsic payoff but also from the "network" value that accrues when others adopt the same technology (Farrell and Saloner, 1985; Katz and Shapiro, 1992). Having a large network of users that also employ the same technology provides external value - positive network externality - to the firm. These network externalities are particularly prevalent in software, apps, social media and communication networks (Brynjolfsson and Kemerer, 1996; Gallaugher and Wang, 2002; Strader et al., 2007; Tucker, 2008; Wattal et al., 2010; Zhou et al., 2015). Infrastructure networks such as ATM machine networks and electronic data interchange systems (Kauffman et al., 2000) also exhibit network externalities. 
Classic economic studies on network externalities provide insight into the pattern of technology adoption in industries that face such network effects. Farrell and Saloner's "lock-in" argument (Farrell and Saloner, 1985, 1986) suggests that the presence of a dominant installed base can inhibit the introduction of new technologies. Buyers exhibit "excess inertia" in their choice of technology arising from the unwillingness to forego the current network externalities from existing technology. In contrast, the economic models of Katz and Shapiro $(1986,1992)$ exhibit the opposite behavior labeled "insufficient friction" that involves a tendency to adopt emerging technologies. In such models, forward-looking buyers of durable products favor new technologies in anticipation that the new technology will provide access to future network externalities. These models identify how potential network benefits affect the technology adoption decision and outcomes.

\section{Switching Costs and Reversibility after Technology Adoption}

Another key factor that affects IT adoption and investment decisions is cost. In addition to the monetary cost of the different technology options, there is also the cost of switching between alternative technologies once a technology has been selected. When a firm selects a new IT solution, and later decides to switch to a different IT solution, such decision involves a switching cost. This cost is higher when different hardware or software options are incompatible and additional investment in software, hardware, and training has to be incurred.

Switching costs effectively can make the technology adoption decision either reversible or irreversible. When the costs of switching from the selected IT solution to the alternative technology option are sufficiently high, technology adoption becomes irreversible.

Choi (1997) as well as Choi and Thum (1998) demonstrate that when switching costs are high, firms may be locked-in into a less-advanced technology. Au and Kauffman (2001) model technology adoption at a financial firm that faces network externalities for the electronic bill presentment and payment (EBPP) technology. In their model, billers are more likely to adopt the safer existing billing technology, even though the new untested technology may later prove to be superior. In this case, firms are cognizant of both potential network benefits and switching costs. If a firm selects a new technology solution, and that solution proves to be inferior, then no other firms will use the same technology and there will be no network benefits. In this scenario, when switching costs are high, such a firm may be prevented from reversing its failed technology selection and switching to the alternative technology that has network benefits. Therefore, a firm selects the technology that already has a strong network of users from the start and avoids new emerging technologies that have no established network of users. Au and Kauffman's results follow from the assumption that switching costs are high and therefore the technology adoption decision is final and irreversible.

In the following section, the impact of switching costs on the technology adoption decision is explored in detail. The theoretical model presented below relaxes the assumptions made in earlier economic models of Choi (1997), Choi and Thum (1998), as well as Au and Kauffman (2001), and demonstrates that while high switching costs may lead to firms selecting technologies that already have a strong network of users, with low switching costs the opposite results are observed. The incentive to try riskier untested technologies is enhanced with low switching costs, as the benefits of a network will still be available to the user through switching if the selection of an untested technology leads to the realization of a lower payoff value. This finding extends the existing economic models and complements the conceptual models such as TAM and UTAUT by demonstrating the impact of the economic factor of switching costs on technology adoption. 


\section{SEQUENTIAL-CHOICE TECHNOLOGY ADOPTION MODEL}

The objective of this section is to consider the implications of different levels of switching costs on technology adoption with two alternative and incompatible technologies when network effects are associated with using the selected technology. This study extends the extant research to allow for different levels of switching costs, thus relaxing the assumption of the irreversibility of technology choice made in earlier studies such as Choi (1997), Choi and Thum (1998), as well as Au and Kauffman (2001). The discussion in this section presents the analytical model and is purposefully kept at an abstract level.

As a brief introduction to the economic model fully developed below, consider the sequential choice of two firms between two alternative information technologies or systems, respectively $A$ and $B$. There is uncertainty about the payoff of each technology. Suppose the first firm has chosen technology $A$. The payoff to choosing $A$ is then realized and observed. When the second firm compares the benefits of choosing $A$ versus $B$, the payoff of technology $B$ is still uncertain. When the switching costs are sufficiently high to make the technology choice irreversible, the second firm fears becoming stranded without a network of followers if the realization of technology $B$ 's payoff is inferior to $A$ 's. If switching costs are low, then the second firm may opt to try technology $B$ because the option of switching back to the tested technology $A$ is still available by paying the switching cost.

Let us now explore the model more formally. Suppose that adopting technology $A$ provides the firm with intrinsic value $\alpha$ as well as the return related to the final size of adoption network $v_{n}$ if $n$ of the $N$ firms adopt technology $A$. Similarly, adopting technology $B$ provides return of $\beta+v_{n}$ if $n$ of the $N$ firms adopt $B$. Returns $\alpha$ and $\beta$ are randomly drawn from certain distribution functions $F$ and $G$, respectively. Table 1 provides a summary of the modeling notation.

Table 1. Description of the Modeling Notation

\begin{tabular}{cc}
\hline Notation & Description \\
\hline$A$ & Technology $A$ \\
$\alpha$ & Technology $B$ \\
$\beta$ & Intrinsic payoff of technology $A$ \\
$v_{n}$ & Intrinsic payoff of technology $B$ \\
$C_{A}$ & Return related to the final size of adoption network if $N$ firms adopt a given technology \\
$C_{B}$ & (i.e. $v_{1}$ if 1 firm adopts the technology) \\
\hline
\end{tabular}

Technologies $A$ and $B$ can be considered "experience goods" in that the value of a technology is discovered only after it has been selected. This value is revealed to all firms when one firm adopts the technology. There is a finite cost $C_{i}$ of switching from technology $i$, and firms cannot delay their adoption decisions.

We start by considering a benchmark case with no network effects. Then, we describe the case of high switching costs and network externalities that is designed to replicate the earlier findings of Choi (1997) as well as Au and Kauffman (2001). We then relax the assumption of the irreversible 
technology adoption that was present in these earlier studies and move on to consider the results for medium switching cost, and low switching cost cases in order to summarize the impact of switching costs on optimal technology adoption decisions.

\section{High Switching Costs and No Network Externalities}

Suppose the first firm adopt technology $A$, and realizes value $\alpha$. For the moment, assume that the switching cost is sufficiently large so that firms adopting technology $A$ will not find it advantageous to switch to the alternative technology. Without network externalities $\left(v_{N}=v_{N-1}=\ldots=v_{1}=0\right)$ the second, risk neutral decision-maker will choose technology $B$ if its expected value, $E(\beta)$, is greater than the realized value of technology $A$. Further, the second decision-maker will not subsequently switch from $B$ to $A$ if the cost of switching is sufficiently large, namely if $\left(C_{B}>\alpha-\beta\right)$, where $\underline{\beta}$ is the lower bound on the distribution of values for technology $B$. In this case, the likelihood of technology $B$ being considered is given by $F(E(\beta))$, the probability that the realized value for $\alpha$ falls below the expected value of $B$.

\section{High Switching Costs and Network Externalities}

Nowletusconsiderthecasewhennetworkexternalitiesarepresentsuch that $v_{N}>v_{n-1}>\ldots>v_{1}=0$. Again let us assume that the first firm chooses technology $A$. Further assume that the $\alpha<E(\beta)$ e cost of switching from $B$ to $A$ is sufficiently high to rule out the second decision-maker switching, namely that $C_{B}>\alpha+\left(v_{N}-v_{1}\right)-\underline{\beta}$. In this case, the second firm will hesitate to select technology $B$, as all other firms will choose $A$ if the realized value of technology $B$ has a comparatively low return, $\beta<\alpha$, resulting in the second firm forgoing the benefit of network externalities. In this situation, the second firm adopts technology $B$ only if the following condition (1) is satisfied.

$$
E(\beta)+(1-G(\alpha))\left[v_{N-1}\right]>\alpha+v_{N}
$$

This replicates the main finding of Choi (1997). Note that the above net gain to choosing technology $B$ is decreasing in $\alpha$. Equation (2) defines the unique value of $\alpha^{*}$ below which the net gain to adopting $B$ is positive.

$$
\alpha^{*}=E(\beta)-\left(v_{N}-v_{N-1}\right)-G\left(\alpha^{*}\right) v_{N-1}
$$

Several conclusions follow from (2). Firstly, technology $B$ may not be adopted even when it has a comparatively high expected value so that . This contrasts with the case of no network externalities in which $B$ is always adopted when it has a higher expected value. Secondly, a mean-preserving increase in the spread of the distribution of returns for technology $B$ indicating a more risky return 
will reduce the likelihood of adopting $B$ as it increases the likelihood of missing out on network externalities.

\section{Medium Switching Costs and Network Externalities}

Now let us focus on the implications of lower switching costs for moving from technology $B$ to $A$. Suppose this cost exceeds the maximum gain from network externalities so that $C_{B}>v_{N}-v_{1}$, but is not sufficiently large to rule out switching if the realized value of payoff $\beta$ is very low, such that $C_{B}<\alpha+\left(v_{N}-v_{1}\right)-\beta$. This medium level of switching costs means that the second firm must perform a different calculation in deciding when to adopt technology $B$ rather than $A$ after the first firm has selected $A$. The second firm now adopts technology $B$ if the following condition holds.

$$
\begin{aligned}
& \left.(1-G(\alpha))[E(\beta \mid \beta \geq \alpha))+v_{N-1}\right] \\
& +\left(G(\alpha)-G\left(\beta_{s}\right)\right)\left[E\left(\beta \mid \beta_{s} \leq \beta<\alpha\right)+v_{1}\right] \\
& \quad+G\left(\beta_{s}\right)\left[\alpha+v_{N}-C_{B}\right]>\alpha+v_{N}
\end{aligned}
$$

The first term on the left indicates the expected return if technology $B$ is shown to be superior to $A$, and all subsequent firms follow the selection of $B$. The second term on the left indicates the expected return if $\beta<\alpha$ in which case no one follows the second firm, but $\beta \geq \beta_{s}=\alpha+\left(v_{N}-v_{1}\right)-C_{B}$ so that it is not advantageous for the second firm to switch to technology $A$ that is used by other adopters. The final term on the left is the gain to the second firm switching back to $A$ after a low realization for technology $B$ 's payoff.

\section{Low Switching Costs and Network Externalities}

Finally, consider the case with network externalities if the cost of switching from $B$ is less than the gain in network externalities, such that $C_{B} \leq\left(v_{N}-v_{1}\right)$. Then the second firm adopts technology $B$ if the following condition holds.

$$
\left.(1-G(\alpha))[E(\beta \mid \beta \geq \alpha))+v_{N-1}\right]+G(\alpha)\left[\alpha+v_{N}-C_{B}\right]>\alpha+v_{N}
$$

Note that if $\beta \geq \alpha$, all subsequent firms will adopt technology $B$. If $\beta<\alpha$, then the second firm will switch to technology $A$ given the switching costs from $B$ to $A$ are outweighed by the network gains when all subsequent firms choose $A$. In this case, the net gain to choosing $B$ is given by equation (5). 


$$
\left.N G_{B}=(1-G(\alpha))[E(\beta \mid \beta \geq \alpha))+v_{N}\right]+G(\alpha)\left[\alpha+v_{N}-C_{B}\right]-\left(\alpha+v_{N}\right)
$$

Note that the above net gain to choosing technology $B$ is decreasing in $\alpha$. There is a unique $\alpha^{*}$ defined by equation (6) at which the net gain is zero.

$$
\alpha^{*}=E(\beta)+G\left(\alpha^{*}\right)\left[\alpha^{*}-E\left(\beta \mid \beta \leq \alpha^{*}\right)-C_{B}\right]
$$

Several conclusions follow from (6). Firstly, technology $B$ may be adopted even though its expected value is below the realized value of $A, E(\beta)<\alpha$. This outcome would occur even without network externalities. Secondly, a mean-preserving increase in the spread of distribution $G$ increases the likelihood that the firm will investigate technology $B$. The conclusions reported in the high switching costs case are thus reversed.

\section{Application of the Model}

The theoretical results above have important implications for IT decision-makers. In considering a project with switching costs that are sufficiently high to make the adoption decision irreversible, the firm would be better off in selecting the tested technology choice already selected by others. If switching costs are low, and the IT investment decision is therefore reversible, then the firm benefits from exploring riskier technology choices. Thus, the economic model demonstrates the impact of switching costs and the reversibility of the IT adoption decision on the type of technology selected.

In order to illustrate the implications of the model, let us explore a number of case studies focusing on technology adoption and the reversibility of technology choice. First, Lee et al. (2003) discuss the microprocessor market, and note that the switching costs for advanced users of server hardware are lower compared with the switching costs in the personal computer (PC) market. This implies that switching between alternative microprocessor technologies is easier in the server market and more difficult in the PC market. Lee et al. describe that the riskier reduced instruction set (RISC) technology became dominant in the server market, while the safer complete instruction set (CISC) technology continued in the personal computer market. The difference in switching costs contributed to the ultimate technology choice by the firms in the way predicted by the theoretical model with the safer technology becoming dominant in the setting of high switching costs and the riskier technology succeeding in the market with lower switching costs.

Second, Krishnan and Bhattacharya (2002) discuss the technology choices of laptop battery design by Dell Computer. The "safe" option was to use the tested and 100-percent operational nickelmetal-hybrid (NiMH) batteries, while the risky option was the lithium-ion technology (LIon). The chances for success of the LIon technology at the time of the decision were evaluated at only 60-percent. The technology choice was not irreversible, as only 30-percent of work on laptop design would have needed to be redone. While prior models (Choi, 1997; Au and Kauffman, 2001) suggested an advantage to the safer technology, the theoretical model presented above shows that with sufficiently low switching costs there are benefits to trying the risky technology. This was the outcome in the Dell case. 
Third, Brynjolfssen and Kemerer (1996) describe the spreadsheet software market in the 1980s and early 1990s, and note that a key switching cost component was the operating system change from DOS to Windows. Existing software written for the DOS operating system had high switching costs for the users, and the dominant Lotus office software exhibited a large price premium. Economy-wide switch to the Windows operating system reduced the switching cost for spreadsheets and office suites as firms already switching to Windows no longer had legacy commitments. Lower switching costs provided an advantage to the emerging Microsoft spreadsheet and office software and reduced the market dominance of the entrenched Lotus spreadsheets. The outcome of this case is again consistent with the theoretical model.

\section{EVIDENCE ON SWITCHING COSTS IN INFORMATION TECHNOLOGY INVESTMENT}

Studies of investment in information technology and information systems have paid much attention to network externalities in technology adoption as benefits of IT often depend on the installed base. A number of both long-established and recent studies provide empirical evidence on network externalities in various sectors of IT industries. Kauffman et al. (2000) find support for network externalities in electronic banking. Brynjolfsson and Kemerer (1996) empirically demonstrate the presence of network externalities in the spreadsheet software market, while Gallaugher and Wang $(1999,2002)$ demonstrate the degree of payoff externalities in the browser/server software market. More recently, the issue of network externalities has been also considered in social media and communication networks (Wattal et al., 2010), e-mail and internet messaging (Strader et al., 2007; Zhou et al., 2015), as well as video-messaging (Tucker, 2008).

As was mentioned above, a key assumption in the existing theoretical models of technology adoption with network externalities is the irreversibility of technology choice. However, case studies demonstrate that the option of reversing technology adoption decision at some switching cost may change the outcome. Empirical studies of network externalities in IT do not focus specifically on potential switching costs of technology adoption, however these studies provide some evidence on the nature of technology options and switching costs in different markets. This evidence is summarized in Table 2.

A review of the literature demonstrates a variety of switching cost experiences in IT. Comparatively low switching costs are described by Krishnan and Bhattacharya (2002) in the Dell battery technology case, Bhattacherjee et al. (2012) in the web browser market, Zhou et al. (2015) in the mobile instant messaging market. In contrast, high switching costs are described by Arora et al. (2010) in a study of internet applications and LAN-based operating systems, as well as Augereau and Greenstein (2001) in a study of the adoption of 56K modems. Kauffman et al. (2000) describe varied technology adoption costs for ATM networks, while Matzler et al. (2015) examine the impact of varied switching costs on the customer satisfaction with IT.

Varied experiences of these IT markets with the costs of switching after a technology has been adopted demonstrate that the assumption of high switching costs that make technology choice irreversible does not describe the entire economy. Even within the same product market, the magnitude of switching costs may shape the market outcome. Lee et al. (2003) note that relating the theoretical predictions on network externalities to the empirical research and case studies in IT is difficult as the existing theories do not provide guidance on the determinants of firm's preference regarding the risk 
Table 2. Evidence on Network Externalities and Switching Costs in IT

\begin{tabular}{ccc}
\hline IT Market & Source(s) & Switching Costs \\
\hline Spreadsheets, Windows OS & Brynjolfsson and Kemerer (1996) & Low \\
Business Computers & Tam and Hui (2001) & Low \\
Laptop Batteries & Krishnan and Bhattacharya (2002) & Low \\
RISC Processors & Lee et al. (2003) & Low \\
Web Browsers & Bhattacherjee et al. (2012) & Low \\
Mobile Instant Messaging & Zhou et al. (2015) & Low \\
Electronic Payment Networks (ATM) & Kauffman et al. (2000) & Varied \\
Automated Payment Systems (ACH) & Gowrisankaran and Stavins (2004) & Varied \\
B2B Computer Services & Matzler et al. (2015) & Varied \\
Spreadsheets, DOS OS & Brynjolfsson and Kemerer (1996) & High \\
Operating Systems & Koski (1999) & High \\
Modems & Augereau and Greenstein (2001) & High \\
CISC Processors & Lee et al. (2003) & High \\
Local Area Networks (LAN) & Corrocher and Fontana (2008) & High \\
Internet applications and LAN OS & Arora et al. (2010) & High \\
\hline
\end{tabular}

level of technology within one model's framework. The theoretical model presented in the previous section extends the literature by removing the irreversibility assumption and incorporates uncertainty in technology adoption decisions to demonstrate the role of switching costs in forming the adoption decision towards either the riskier or the safer technology.

\section{CONCLUSIONS AND IMPLICATIONS}

This study presents an original theoretical model that provides new analytical results on the role of switching costs and reversibility in the adoption decisions for IT markets that exhibit network externalities. As a firm considers the adoption decision for new technologies that yield uncertain payoffs and are subject to network externalities, the irreversible adoption case means that safer tested technologies have an advantage. With low switching costs, however, the technology adoption decision is reversible and there is a benefit to trying a riskier untested technology that may prove to be superior. This analytical result extends the existing economic models of technology adoption and complements such conceptual models as TAM and UTAUT by describing the impact of the economic factor of switching cost.

The model provides clear managerial implications for the MIS and IT decision makers. It suggests that firms considering technological solutions that do not involve irreversible commitment will see a benefit of selecting riskier untested technologies. If switching costs are sufficiently high to make the adoption decision irreversible, then safer technology provides an advantage to the firm.

Several directions for future research may be identified as the theoretical model provides clear predictions that may be tested empirically. Existing empirical studies of network externalities in 
the MIS literature have not focused on the specific issue of reversibility in IT adoption. However, the empirical evidence reviewed above describes varied experiences across IT markets in the scale of switching costs and the reversibility of technology choices made by the firms. A systematic identification of empirical data that allows for testing of the theory is an area of future research. This work may be complemented by performing simulation exercises designed to illustrate the workings of the theoretical model. Recent economic experiments explored the role of switching costs in technology adoption (Keser et al., 2012) suggesting that the findings of this study may also be tested experimentally.

Innovation in IT involves uncertainty about the payoff from investment and the level of risk associated with selecting each of the available technology options. Network externalities are encountered in a wide variety of IT settings. Innovation funding and investment decisions in these cases would benefit from a better understanding of the impact of decision reversibility and switching costs on technology adoption and investment.

\section{REFERENCES}

Arora, A., Forman, C., \& Yoon, J. (2010). Complementarity and information technology adoption: Local area networks and the Internet, Information Economics and Policy, 22, 228-242.

Au, Y., Kauffman, R.J. (2001). Should we wait? Network externalities, compatibility, and electronic billing adoption, Journal of Management Information Systems, 18, 47-63.

Augereau, A., Greenstein, S. (2001). The need for speed in emerging communications markets: upgrades to advanced technology at Internet Service Providers, International Journal of Industrial Organization, 19, 1085-1102.

Bhattacherjee, A., Limayem, M., \& Cheung, C. M. (2012). User switching of information technology: A theoretical synthesis and empirical test. Information \& Management, 49(7), 327-333.

Brynjolfssen, E., Kemerer, C. (1996). Network externalities in microcomputer software: an econometric analysis of the spreadsheet market, Management Science, 42, 1627-1647.

Choi, J. (1997). Herd behavior, the "penguin effect", and the suppression of informational diffusion: an analysis of informational externalities and payoff interdependency, RAND Journal of Economics, 28, 407425.

Choi, J., Thum, M. (1998). Market structure and the timing of technology adoption with network externalities, European Economic Review, 42, 225-244.

Corrocher, N., Fontana, R. (2008). Expectations, network effects and timing of technology adoption: some empirical evidence from a sample of SMEs in Italy, Small Business Economics, 31, 425-441.

Farrell, J., Saloner, G. (1985). Standardization, compatibility and innovation, RAND Journal of Economics, $16,70-86$.

Farrell, J., Saloner, G. (1986). Installed base and compatibility: Innovation, product preannouncements and predation, American Economic Review, 76, 940-955.

Farzin, Y., Huisman, K., \& Kort, P. (1998) Optimal timing of technology adoption, Journal of Economic Dynamics and Control, 22 (5), 779-799.

Gallaugher, J., Wang, Y. (1999). Network externalities and the provision of composite IT products supporting the e-commerce infrastructure, Electronic Markets, 9, 14-19. 
Gallaugher, J., Wang, Y. (2002). Understanding network effects in software markets: Evidence from web server pricing, MIS Quarterly, 26, 303-327.

Gangwar, H., Date, H., \& Raoot , A.D. (2014). Review on IT adoption: insights from recent technologies, Journal of Enterprise Information Management, 27, 488 - 502.

Ghezzi, A., Rangone, A., \& Balocco, R. (2013). Technology diffusion theory revisited: a regulation, environment, strategy, technology model for technology activation analysis of mobile ICT. Technology Analysis \& Strategic Management, 25(10), 1223-1249.

Gowrisankaran, G., Stavins, J. (2004). Network externalities and technology adoption: Lessons from electronic payments, RAND Journal of Economics, 35, 260-276.

Hagspiel, V., Huisman, K., \& Nunes, C. (2015) Optimal technology adoption when the arrival rate of new technologies changes, European Journal of Operational Research, 243 (3), 897-911.

Kamal, M. (2006). IT innovation adoption in the government sector: identifying the critical success factors, Journal of Enterprise Information Management, 19, 192 - 222.

Katz, M., Shapiro, C. (1986). Technology adoption in the presence of network externalities, Journal of Political Economy, 94, 822-841.

Katz, M., Shapiro, C. (1992). Product introduction with network externalities, Journal of Industrial Economics, 40, 55-83.

Kauffman, R.J., McAndrews, J., \& Wang, Y. (2000). Opening the "black box" of network externalities in network adoption, Information Systems Research, 11, 61-82.

Keser, C., Suleymanova, I., \& Wey, C. (2012). Technology adoption in markets with network effects: Theory and experimental evidence, Information Economics and Policy, 24, 262-276.

Koski, H. (1999). The installed base effect: Some empirical evidence from the microcomputer market, Economics of Innovation and New Technology, 8, 273-310.

Krishnan, V., Bhattacharya, S. (2002). Technology selection and commitment in new product development: The role of uncertainty and design flexibility, Management Science. 48, 313-327.

Lee, J., Lee, J., \& Lee, H. (2003). Exploration and exploitation in the presence of network externalities, Management Science, 49, 553-570.

Matzler, K., Strobl, A., Thurner, N., \& Füller, J. (2015). Switching experience, customer satisfaction, and switching costs in the ICT industry. Journal of Service Management, 26(1), 117-136.

Roy, S. (2017) App Adoption and Switching Behavior: Applying the Extended TAM in Smartphone App Usage, Journal of Information Systems and Technology Management, 14 (2), 239-261.

Strader, T., Ramaswami, S., \& Houle, P. (2007). Perceived network externalities and communication technology acceptance, European Journal of Information Systems, 16, 54-65.

Tam, K., Hui, K. (2001). A choice model for the selection of computer vendors and its empirical estimation, Journal of Management Information Systems, 17, 97-124.

Tucker, C. (2008). Identifying formal and informal influence in technology adoption with network externalities. Management Science, 54, 2024-2038.

Venkatesh, V., Morris, M. G., Davis, G. B., \& Davis, F. (2003). User Acceptance of Information Technology: Toward a Unified View, MIS Quarterly, 27 (3), 425-478

Venkatesh, V., Thong, J. Y., \& Xu, X. (2012). Consumer acceptance and use of information technology: extending the unified theory of acceptance and use of technology. MIS quarterly, 36 (1), 157-178. 
Wattal, S., Racherla, P., \& Mandviwalla, M. (2010). Network externalities and technology use: A quantitative analysis of intra-organizational blogs, Journal of Management Information Systems, 27, 145-173.

Zhou, T., Li, H., \& Liu, Y. (2015). Understanding mobile IM continuance usage from the perspectives of network externality and switching costs. International Journal of Mobile Communications, 13(2), 188203. 